\title{
Canine Visceral Leishmaniasis in Colombia Resistant to the Treatment of Choice (Meglumine Antimoniate Plus Allopurinol)
}

\author{
Juan Carlos Pinilla ${ }^{1 *}$, Arturo Gutierrez ${ }^{2}$ and Angel Alberto Florez ${ }^{1}$ \\ ${ }^{1}$ Universidad de Santander, Facultad de Ciencias Exactas, Naturales y Agropecuarias, Grupo de Investigación en \\ Ciencias Agropecuarias-GICA, Bucaramanga, Colombia; ${ }^{2}$ Universidad Industrial de Santander, Facultad de Salud, \\ Escuela de Microbiología, Grupo de Inmunología y Epidemiología Molecular-GIEM, Bucaramanga, Colombia \\ *Corresponding author: jcpinilla65@gmail.com
}

Article History: 21-318 Received: 15-May-21 Revised: 24-Jul-21 Accepted: 29-Jul-21
A BS TRA C T
This paper describes a case of canine visceral Leishmaniasis resistant to Meglumine Antimoniate plus allopurinol
treatment in a canine patient from Colombia. A one-year-old castrated dog of the schnauzer breed was referred for
veterinary consultation for showing a 2-month history of dermatological lesions on the back of the body and tail.
Clinical examination revealed circular and ulcerative alopecic lesions delimited by a high relief border. Based on the
clinical examination and laboratory analysis, canine leishmaniasis by Leishmania infantum was established as a
diagnosis. The patient was treated with Glucantime $\AA$ (50mg/kg subcutaneously twice daily for 4 weeks) plus
Allopurinol ${ }^{\circledR}(10 \mathrm{mg} / \mathrm{kg}$ twice a day orally for 10 months). Eight weeks after began treatment lesions had disappeared.
However, two months later there was a clinical relapse. To our knowledge, it is the first report of resistance of canine
Leishmaniasis to Glucantime ${ }^{\circledR}$ plus allopurinol in Colombia.

Key words: Canine; Colombia; Leishmania infantum; Meglumine antimoniate

\section{INTRODUCTION}

Leishmaniasis is a vector-borne disease parasitic caused by kinetoplastids from the genus Leishmania. Dogs can be infected by several Leishmania spp. and are considered the main reservoir of Leishmania infantum, the aethiological agent of human and canine visceral leishmaniasis (dos Santos Nogueira et al. 2019; DantaTorres et al. 2019).

Clinical signs in L. infantum-infected dogs are variable and may be present from three months to several years after dogs become infected (Ribeiro et al. 2018). The main clinical findings based on physical examination in classical canine visceral leishmaniasis include skin lesions, generalized adenopathy, lack of appetite, weight loss, muscular atrophy, exercise intolerance, splenomegaly, polyuria and polydipsia, epistaxis, onychogryphosis, vomiting and diarrhea (Ribeiro et al. 2018). Skin lesions are a very common manifestation of the disease. Various cutaneous forms such as alopecia, exfoliative, ulcerative, nodular or sterile pustular dermatitis in the different parts of the body have been described (Ribeiro et al. 2018).

World Health Organization (WHO) has suggested the use of antileishmanial drugs exclusively for the treatment of human leishmaniasis, in order to avoid possible drugresistance due to their use in veterinary medicine, and to avoid future problems in the treatment and control disease. Nevertheless, the resistance of $L$. infantum strains to antimonials is becoming a major public health problem (Adel et al. 2015). In this sense, Vélez et al. (2009) reported visceral leishmaniasis resistance in two people who did not respond to treatment with Pentavalent amonials drugs. Nevertheless, the choice treatment for canine leishmaniasis is currently the combined use of antileishmanial drugs used for humans, as pentavalent antimonial and allopurinol (Miró et al. 2017; Travi et al. 2018). Therefore, the aim of this clinical case was to describe a canine visceral Leishmaniasis resistant to Meglumine Antimoniate plus allopurinol treatment.

\section{MATERIALS AND METHODS}

\section{Ethical Statement}

The authors declare that the present research work was conducted in an ethical manner according to International Guiding Principles for Biomedical Research Involving Animals.

Cite This Article as: Pinilla JC, Gutierrez A and Florez AA, 2022. Canine visceral leishmaniasis in Colombia resistant to the treatment of choice (meglumine antimoniate plus allopurinol). International Journal of Veterinary Science 11(1): 117-120. https://doi.org/10.47278/journal.ijvs/2021.103 


\section{History and Clinical Examination}

A one-year-old castrated dog of the schnauzer breed was referred for veterinary consultation in a private veterinary clinic in the Bucaramanga city, Santander department, Colombia, with a 2-month history of dermatological lesions on the back of the body and tail in the patient. The owner reported that his dog has shown a lack of appetite and progressive loss of weight for about two weeks. Clinical examination revealed circular and ulcerative alopecic lesions on the back of the body and tail (Fig. 1A,1B). These lesions were not painful or pruritic, and were delimited by a high relief border, and apparent loss of only the dermal layer. Physical examination revealed that the corporal condition score was $4 / 5$, a temperature of $38.5^{\circ} \mathrm{C}$, and physiological constants (heart rate, respiratory rate, or pulse) were in the normal ranges. On palpation, the popliteal lymph nodes were enlarged. Based on the information obtained in the medical history and clinical examination, canine leishmaniasis was established as a presumptive diagnosis. Hematology and blood chemistry were performed. A biopsy of the dermatological lesion for histopathological study, and the SNAP ${ }^{\circledR}$ Canine $L$. infantum Antibody Test (IDEXX Laboratories, Inc., Westbrook, Maine, USA), were used for confirming the diagnosis, with a $96.3 \%$ of sensitivity and $99.2 \%$ of specificity (IDEXX Laboratories).

Hematology results (Table 1) show an increase in hematocrit and hemoglobin indicating dehydration. The series of white cells show leukocytosis with neutrophilia, indicating the presence of an acutely evolving bacterial infectious process. Platelet values were within normal parameters. Table 2 shows the blood chemistry results for liver and kidney assessment. The values found were within the reference values.

According to the skin biopsy, a histopathological description was done of a superficial and deep dermis with diffuse multinodular infiltrate with mixed leukocyte reaction of histiocytes, epithelioid and multinucleated Langhian's-like cells, eosinophils and structures compatible with amastigotes. Atrophy of the epidermis with a continuous diffuse area of necrosis, adnexal atrophy and collagen fragmentation was also observed, showing a diagnosis of superficial and deep granulomatous dermatitis compatible with cutaneous Leishmaniasis. Figure 2 shows the test for detection of anti-L.infantum antibodies. It is appreciated that the positive control spot and the sample spot are colored, indicating the positivity of the patient. The color development is proportional to the concentration of specific anti-Leishmania antibodies in whole dog blood (IDEXX Laboratories).

Once the diagnosis of visceral leishmaniasis by $L$. infantum was established, the patient was treated with meglumine antimoniate $(50 \mathrm{mg} / \mathrm{kg}$ subcutaneously twice daily for 4 weeks) (Glucantime ${ }^{\circledR}$ Merial Laboratory, Barcelona - Spain), $10 \mathrm{mg} / \mathrm{kg}$ of allopurinol orally twice a day for 10 months (Allopurinol ${ }^{\circledR}$ American generics Laboratory, Bogota - Colombia), and disinfection of the lesions with chlorhexidine topical solution (Hexocleen Spray®, Invet laboratories S.A.; Bogotá-Colombia) twice daily for a month. Hematology and blood chemistry were performed during the treatment to check liver and renal functions. Two months after starting treatment, the dog was brought for clinical consultation; and lesions had disappeared. However, two months later there was a clinical relapse with appear dermatological lesions on the back of the body. Moreover, Leishmania amastigotes were observed in smears obtained by impression from skin lesions. The cytological smears were stained with Giemsa (Fig. 3).
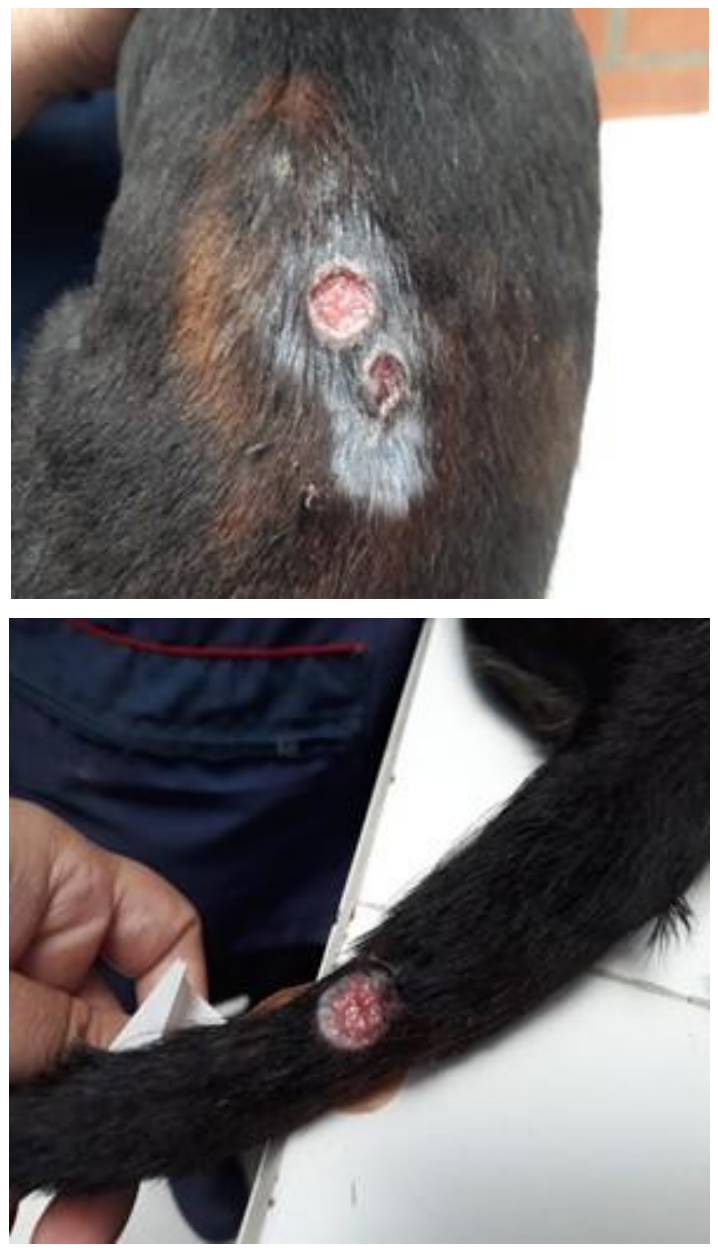

Fig. I: A) Two dermatological lesions over the back region. B) One dermatological lesion on the tail of the canine.

Table I: Hematology results in a canine patient with leishmaniasis before treatment

\begin{tabular}{llll}
\hline Parameters & Unit & Results & Reference values* \\
\hline Red blood cell count & $\times \mathrm{mm}^{3}$ & $8.76 \times 10^{12}$ & $5.4-10.3$ \\
Hematocrit & $\%$ & 57.8 & $37-45$ \\
Hemoglobin & $\mathrm{mg} / \mathrm{dL}^{*}$ & 16.1 & $\mathrm{II} .8-14.5$ \\
White blood cell count & $\times \mathrm{mm}^{3}$ & $14.5 \times 10^{3}$ & $6,000-1 \mathrm{I}, 000$ \\
Neutrophils & $\%$ & 75 & $60-70$ \\
Lymphocytes & $\%$ & 16 & $12-30$ \\
Eosinophils & $\%$ & 5 & $\mathrm{I}-5$ \\
Monocytes & $\%$ & 4 & $0-2$ \\
Basophils & $\%$ & 0 & $0-2$ \\
Band cells & $\%$ & 0 & $0-2$ \\
Platelet cell counts & $\times \mathrm{mm}^{3}$ & 307,000 & $150,000-450,000$ \\
\hline
\end{tabular}

Pedrozo et al. (20l0).

Table 2: Blood chemistry results in a canine patient with leishmaniasis before treatment

\begin{tabular}{llll}
\hline Parameters & Units & Results & Reference values* \\
\hline ALT & $\mathrm{U} / \mathrm{L}$ & 10.7 & $\mathrm{I} 4-55$ \\
AST & $\mathrm{U} / \mathrm{L}$ & $\mathrm{I} 5$ & $2 \mathrm{I}-58$ \\
Alkaline phosphatase & $\mathrm{U} / \mathrm{L}$ & 32 & $<300$ \\
BUN & $\mathrm{mg} / \mathrm{dL}$ & $\mathrm{II}$ & $8-29$ \\
Creatinine & $\mathrm{mg} / \mathrm{dL}$ & 0.74 & $0.6-1.5$ \\
\hline
\end{tabular}

"Latimer (2005). 


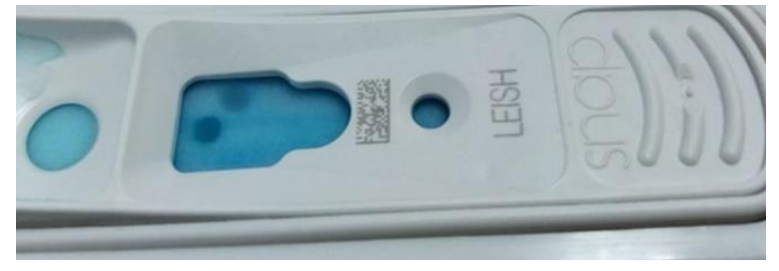

Fig. 2: $S N A P \circledast$ Canine Leishmania infantum Antibody Test. Positive control spot and the sample spot are colored.

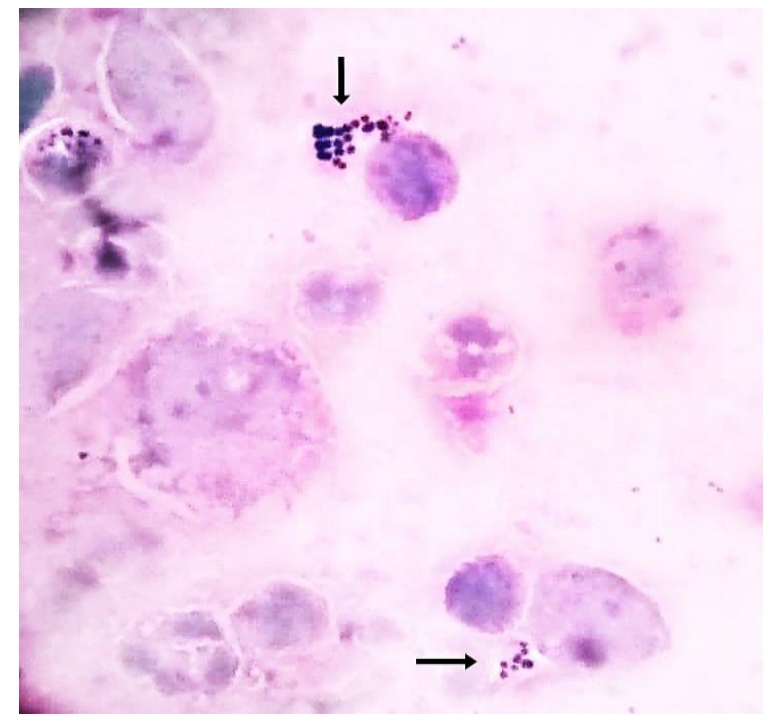

Fig. 3: Leishmania amastigotes near macrophage (arrows).

\section{DISCUSSION}

Our study describes a case of canine visceral leishmaniasis due to infection by $L$. infantum resistant to treatment with Meglumine Antimoniate + Allopurinol in a dog from an endemic area for canine leishmaniasis. According to the literature consulted, this clinical case described is probably the first report of leishmania resistance to Glucantime ${ }^{\circledR}$ plus allopurinol treatment in a canine patient from Bucaramanga, Colombia. Probably, there are no canine Leishmaniasis treatment failure cases reported in Colombia.

According to WHO (2010), leishmaniasis is a zoonotic and prevalent disease in more than 98 worldwide countries, especially in regions of southern Europe, Africa, Asia, and South America and Central America. In Colombia, it is endemic in almost the entire national territory and represents a public health problem. According to the National Institute of Health (INS 2018), it is estimated that in the country there are more than 11 million people at risk, and $98 \%$ of Leishmaniasis cases correspond to the tegumentary form (INS 2018). However, there is visceral leishmaniasis focus in different departments of the middle Magdalene region such as Santander.

Despite the WHO suggesting the exclusive use of antimonial drugs in the treatment of human leishmaniasis, choice treatment for canine leishmaniasis is currently the combined use of leishmanicidal agents used for human, as pentavalent antimonial and allopurinol (Miró et al. 2017; Travi et al. 2018). Since the beginning of the twentieth century, the therapeutic effects of these compounds against leishmania have been described, and therefore remain as drugs of choice against canine leishmaniasis around the world (alone or combined with allopurinol) (Medkour et al. 2020). In this sense, the recommended therapeutic scheme for canine leishmaniasis is meglumine antimoniate (Glucantime ${ }^{\circledR}$ ) injected subcutaneously at a dose daily of $100 \mathrm{mg} / \mathrm{kg}$ for one month together with allopurinol administered orally $10 \mathrm{mg} / \mathrm{kg}$ twice a day for six months minimum (Solano-Gallego et al. 2011; 2016; Manna et al. 2015; Ribeiro et al. 2018). However, the prolonged use of meglumine antimoniate could cause nephrotoxic problems, while allopurinol problem of xanthinuria, renal mineralization and urolithiasis (SolanoGallego et al. 2011).

Currently, different Leishmania strains can resist the antimonial pentavalent, which generates low reliability in the treatment. In some countries, this resistance can exceed $40 \%$ of the cases (Acero et al. 2015). Therefore, in America, treatment of canines with visceral leishmaniasis is not recommended because the dogs will not be cured even though they clinically show an improvement in the clinical signs, clinical relapses are constant, Leishmania strains may become resistant, and the treatment is not commercially available. For such reason, most of the time slaughtering dogs is recommended (Acero et al. 2015).

Several factors have been reported as possible causes of anti-leishmanial treatment failure, e.g., host immune response, physiological disorders that affect the tissue deposits of the antimoniate and lack of response to antimoniate therapy due to genetic predisposition (Vélez et al. 2009). Furthermore, parasitic factors such as structural modifications of the target proteins or mechanisms to evade the host's immune system have also been pointed out (Miro'G et al. 2017). Another relevant aspect about the chemotherapeutic treatment against canine leishmaniasis is the onset of drug-resistant strains when wrong dosages are used, even failures of the combination Glucantime/allopurinol therapy have been reported, mainly due to the drug-resistance of Leishmania, but time to relapse in treated dogs has not been documented (Medkour et al. 2020). In this sense, the Leishmania resistance against a given drug may be acquired when the leishmania parasites are treated with suboptimal drug doses (Vélez et al. 2009). However, in the present clinical case, the therapeutic management was suggested by the experts, therefore, the failure of the treatment cannot be attributed to a resistant strain that survived at suboptimal doses used.

Clinical recurrences in canine leishmaniasis often occur after treatments, however, it is necessary to consider that the available protocols can provoke clinical cure, improve the life expectancy, and increase the quality of life, in addition to reducing the parasite load and infectiousness to sand fly vectors. However, further studies should be conducted to design new drugs to completely cure canine leishmaniasis. However, further studies should be conducted to design new drugs to completely cure canine leishmaniasis.

\section{Conclusion}

Reports about the resistance of canine visceral leishmaniasis by $L$. infantum to glucantime plus allopurinol treatment are scarce. According to the literature consulted, it is the first report of resistance of 
canine Leishmaniasis to Glucantime ${ }^{\circledR}$ plus allopurinol in Colombia.

\section{Author's Contribution}

JCP and AG managed the case at the veterinary clinic. All authors revised and approved the final manuscript to submission to the journal.

\section{Acknowledgments}

The authors thank the University of Santander for their help in the funding of this work.

\section{REFERENCES}

Acero V, Ángel P, Fonseca E, Ferrer L and Roura X, 2015. Leishmaniosis canina: herramientas para el diagnóstico en la consulta veterinaria en Colombia. Revista MVZ Córdoba 20: 4822-4842.

Adel A, Abatih E, Speybroeck N, Soukehal A, Bouguedour R, Boughalem K, Bouhbal A, Djerbal M, Saegerman C and Berkvens D, 2015. Estimation of canine Leishmania infection prevalence in six cities of the Algerian littoral zone using a Bayesian approach. PLoS One 10: e0117313. https://doi.org/10.1371/journal.pone.0117313

Dantas-Torres F, Miró G, Baneth G, Bourdeau P, Breitschwerdt E, Capelli G, Cardoso L, Day M, Dobler G, Ferrer L, Irwin P, Jongejan F, Kempf V, Kohn B, Lappin M, Little S, Madder M, Maggi R, Maia C, Marcondes M, Naucke T, Oliva G, Pennisi M, Penzhorn B, Peregrine A, Pfeffer M, Roura X, Sainz A, Shin S, Solano-Gallego L, Straubinger R, Tasker S, Traub R, Wright I, Bowman D, Gradoni L and Otranto D, 2019. Canine leishmaniasis control in the context of one health. Emerging Infectious Diseases 25: 14. https://doi.org/10.3201/eid2512.190164

dos Santos Nogueira F, Avino V, Galvis-Ovallos F, PereiraChioccola V, Batistella M, Peres A, Romariz L, Molla L and Menz I, 2019. Use of miltefosine to treat canine visceral leishmaniasis caused by Leishmania infantum in Brazil. Parasites Vectors 12: 79. https://doi.org/10.1186/ s13071-019-3323-0

Instituto Nacional de Salud, 2018. Informe del evento Leishmaniasis cutánea, visceral y mucosa, Colombia 2018. Available at: https://www.ins.gov.co/buscador-eventos /Informesdeevento/LEISHMANIASIS 2018.pdf

Latimer K, Prassee K and Mahaffey E, 2005. Patología clínica veterinaria. 4th Ed. Multimédica Ediciones Veterinarias, Mexico, pp: 492.
Manna L, Corso R, Galiero G, Cerrone A, Muzj P and Gravino A, 2015. Long-term follow-up of dogs with leishmaniosis treated with meglumine antimoniate plus allopurinol versus miltefosine plus allopurinol. Parasites Vectors 8: 289. https://doi.org/10.1186/s13071-015-0896-0

Medkour H, Bitam I, Laidoudi Y, Lafri I, Lounas A, Hamidat HK, Mekroud A, Varloud M, Davoust B and Mediannikov $\mathrm{O}, 2020$. Potential of artesunate in the treatment of visceral leishmaniasis in dogs naturally infected by Leishmania infantum: Efficacy evidence from a randomized field trial. PLoS Neglected Tropical Disease 14: e0008947. https://doi.org/10.1371/journal.pntd.0008947

Miro ${ }^{\prime}$ G, Petersen C, Cardoso L, Bourdeau P, Baneth G, SolanoGallego L, Pennisi M, Ferrer L and Oliva G, 2017. Novel areas for prevention and control of canine leishmaniosis. Trends in Parasitology 20: 1-13. https://doi.org/10.1016/ j.pt.2017.05.005

Pedrozo R, Quintana G, Bazán A and Florentín M, 2010. Valores hematológicos de referencia en caninos adultos aparentemente sanos, que concurren a una clínica privada de Asunción. Memorias del Instituto Investigación en. Ciencias de Salud 8: 5-13.

Ribeiro R, Marques M, da Silva M, Peixoto C, Georges F and da Silva S, 2018. Canine leishmaniasis: An overview of the current status and strategies for control. BioMed Research International 2018: Article 3296893. https://doi.org/ $10.1155 / 2018 / 3296893$

Solano-Gallego L, Mir'o G, Koutinas A, Cardoso L, Pennisi M, Ferrer L, Bourdeau P, Oliva G and Baneth G, 2011. LeishVet guidelines for the practical management of canine leishmaniasis. Parasites Vectors 4:86. https://doi.org /10.1186/1756-3305-4-86

Solano-Gallego L, Di Filippo L, Ordeix L, Planellas M, Roura X, Altet L, Martínez-Orellana P and Montserrat S, 2016 Early reduction of Leishmania infantum-specific antibodies and blood parasitemia during treatment in dogs with moderate or severe disease. Parasites Vectors 9: 235. https://doi.org/10.1186/s13071-016-1519-0

Travi B, da Silva C, Dantas-Torres F and Miro', G, 2018. Canine visceral leishmaniasis: Diagnosis and management of the reservoir living among us. PLoS Negleted Tropical Disease 12: e0006082. https://doi.org/10.1371/journal. pntd.0006082

Vélez I, Colmenarez L and Muñoz, C, 2009. Two cases of visceral leishmaniasis in Colombia resistant to meglumine antimonial treatment. Case report. Revista do Instituto de Medicina Tropical de São Paulo 51: 231-236. https://doi.org/10.1590/S0036-46652009000400011 